\title{
Prevalence of Porphyromonas gingivalis fimA II genotype in generalized aggressive periodontitis patients
}

\author{
Richelle Soares Rodrigues', Catarina Martins Tahim¹, Virgínia Regia Silveira², Nadia Accioly Pinto Nogueira², \\ Rodrigo Otavio Rego ${ }^{2 *}$
}

'DDS, MS, Universidade Federal do Ceará(UFC), Graduate Program in Dentistry, School of Pharmacy, Dentistry and Nursing, Fortaleza, CE, Brazil ${ }^{2}$ DDS, MS, PhD, Universidade Federal do Ceará(UFC), Department of Dentistry, School of Dentistry at Sobral, Sobral, CE, Brazil

${ }^{3} \mathrm{MSc}, \mathrm{PhD}$, Universidade Federal do Ceará(UFC), Department of Clinical and Toxicological Analyses, School of Pharmacy, Dentistry and Nursing,

Fortaleza, CE, Brazil

Received for publication: December 2, 2016 Accepted: April 19, 2017

Correspondence to: Rodrigo Otavio Rêgo Federal University of Ceara School of Dentistry at Sobral St. Estanislau Frota, s/n, Sobral-CE 62.011-000, Brazil

E-mail: rodrigorego@yahoo.com Tel/Fax: +558533668232

\begin{abstract}
Purpose: The objective of this study was to evaluate the prevalence of Porphyromonas gingivalis $(\mathrm{Pg})$ and its fimA II genotype in a sample of Brazilian patients with generalized aggressive periodontitis (GAgP) and to correlate the presence of each pathogen/genotype with clinical parameters. Methods: We used polymerase chain reaction (PCR) to evaluate the presence of $P g$ and fimA II genotype in subgingival plaque samples collected from the deepest site of 45 Brazilian patients aged $15-40$ years with GAgP and correlated findings with age and clinical parameters (plaque index, gingival bleeding index, probing depth and clinical attachment loss). Results: $P g$ was identified in $64.4 \%$ patients. FimA II genotype was present in $82.6 \%$ of $P$ g-positive patients. The presence of $P g$ and fimA II genotype was significantly associated with greater clinical attachment loss at the sampled periodontal site. Pg-positive patients were slightly older than Pg-negative patients. Conclusions: $P g$ and fimAll genotype were highly prevalent in Brazilian patients with GAgP. Pg was more commonly observed in slightly older individuals and in sites with more clinical attachment loss.
\end{abstract}

Keywords: Aggressive periodontitis. Bacterial fimbriae. Porphyromonas gingivalis.

\section{Introduction}

Aggressive periodontitis ( $\mathrm{AgP})$ is a rapidly progressive form of periodontitis affecting systemically healthy patients ${ }^{1}$. Less common and more severe than chronic periodontitis, AgP tends to run in families, with a preference for younger individuals ${ }^{2}$. Such characteristics suggest the presence of highly virulent pathogens and/or a high level of susceptibility to the disease ${ }^{1,2}$. Over the past few years, much research has been conducted on the etiology and pathogenesis of $\mathrm{AgP}^{3,4}$.

Strong evidence exists for the role of Aggregatibacter actinomycetemcomitans (Aa), especially the JP2 clone, as an etiological factor in the pathogenesis of $\mathrm{AgP}^{5}$. However, in some populations $\mathrm{Pg}$ can also be associated to $\mathrm{AgP}^{3,4}$. This organism displays great genotypical and phenotypical diversity resulting in variations in virulence and ability to induce periodontal destruction ${ }^{6}$. The virulence of $P g$ is consistently associated with the presence of fimbriae, structures related to cell adhesion? ${ }^{7}$.

The fimbriae play an important role in the invasion and colonization of periodontal tissues $^{8}$. Fimbrillin $(f i m A)$, a subunit protein of the fimbriae in this organism, is encoded 
by the fim $A$ gene ${ }^{6,9}$. Based on nucleotide sequence, six fim $A$ genotypes have been identified: fim $A$ I, Ib, II, III, IV and $V^{7,9,10}$. FimA II is the most prevalent in patients with periodontitis, usually followed by FimA IV and $\mathrm{Ib}^{6,9}$. The genotypical diversity of fimA genotype has been evaluated for a range of periodontal conditions, but to our knowledge only two studies have focused on $\mathrm{AgP}^{3,11}$. In these studies, $\mathrm{AgP}$ was strongly associated with genotype fimA II in Japanese ${ }^{11}$ and Chinese subjects $^{3}$.

Microbiological variations in $\mathrm{AgP}$ patients related to ethnicity and socio-demographic conditions justify conducting studies on different populations ${ }^{12,13}$. In addition, by correlating the presence of periodontal pathogens with clinical parameters, individuals at risk may be identified. Thus, we evaluated the prevalence of $\mathrm{Pg} /$ fimA II genotype in generalized aggressive periodontitis (GAgP) Brazilian patients and correlated the presence of each pathogen/genotype with clinical parameters.

\section{Material and methods}

\section{Selection of subjects}

This study was conducted in $45 \mathrm{GAgP}$ patients selected at the Periodontology Clinic of the School of Pharmacy, Dentistry and Nursing, at the Federal University of Ceara, Brazil.

GAgP patients were classified according to the clinical criteria suggested by the American Academy of Periodontology2: generalized interproximal attachment loss affecting at least three permanent teeth other than the first molars and incisors in systemically healthy individuals with rapid attachment loss and bone destruction. To be eligible for the study, patients had to be aged 12-40 years and have at least 20 teeth other than third molars, of which at least three first molars and five incisors. The clinical diagnosis was confirmed by evidence of inter-proximal bone loss on full-mouth periapical radiographs.

The exclusion criteria were as follows: periodontal treatment within the previous 6 months, antibiotic therapy within the previous 3 months, smoking habits and systemic changes capable of interfering with periodontal health.

The research protocol was approved by the Ethics Committee of the Federal University of Ceara, Brazil (no 20/08). After being informed about the purpose of the study, all participants or guardians gave their written consent.

\section{Clinical measurements}

Clinical measurements were made on all the completely erupted permanent teeth, except the third molars, using a periodontal probe (PCP-UNC 15, Trinity, São Paulo, SP, Brazil). The following parameters were evaluated: plaque index $(\mathrm{PI})^{14}$, gingival index $(\mathrm{GI})^{14}$, probing depth $(\mathrm{PD})$ and clinical attachment loss (CAL). PD and CAL were taken at six sites per tooth (mesiobuccal, buccal, distobuccal, mesiolingual, lingual, and distolingual). A single examiner evaluated all the clinical periodontal parameters, and measurement reproducibility was calculated by using the intraclass correlation coefficient (ICC) for PD and CAL. The agreement between replicate measurements was high $(\mathrm{ICC}>0.80)$.

\section{Microbiological sampling and evaluation}

The supragingival plaque was removed with curettes and sterile cotton pellets, and the area was isolated with sterile cotton rolls. Subgingival plaque samples were collected by means of two sterile paper points (Dentsply Maillefer 35, Dentsply, Rio de Janeiro, RJ, Brazil) at the selected site for 20 seconds. The selected site was the proximal site with the greatest PD and CAL of molars or incisors of each patient. The samples were separately immersed in microtubes containing $1 \mathrm{~mL}$ Ringer's sterile solution ${ }^{15}$ and stored at $-80^{\circ} \mathrm{C}$ until they were processed.

Each sample was processed separately. The microtubes containing the samples were thawed on ice. The bacterial cells or suspension were dispersed by vortexing at the maximum setting for $1 \mathrm{~min}$ and centrifuged at $12,000 \mathrm{x} \mathrm{g}$ for $10 \mathrm{~min}$. Genomic DNA was extracted from the pellet (InstaGene Matrix, Bio-Rad Laboratories, Hercules, CA, USA) and a $20 \mu \mathrm{L}$ aliquot of the resulting supernatant was added to $30 \mu \mathrm{L}$ reaction mixture containing $25 \mu \mathrm{M}$ PCR buffer (Promega Corporation, Madison, WI, USA), $25 \mu \mathrm{M} \mathrm{MgCl}_{2}$ (Promega Corporation, Madison, WI, USA), $0.2 \mu \mathrm{M}$ dNTP mix (Promega Corporation, Madison, WI, USA), 1.25 U Taq polymerase (Promega Corporation, Madison, WI, USA), and $100 \mathrm{ng}$ of each primer (Invitrogen, São Paulo, SP, Brazil), resulting in a final volume of 50 $\mu \mathrm{L}^{16}$. Negative and positive controls were included in each reaction.

First, PCR was performed with universal primers (5'-GGACT A Y A GGGT A TCT A A T - 3'; $5^{\prime}$-AGAGTTTGATCMTGG-3 $\left.{ }^{\prime}\right)^{17}$ for the $16 \mathrm{~S}$ ribosomal DNA (16S rDNA) to confirm the presence of bacterial DNA. Subsequently, the samples were evaluated by PCR with specific primers for the presence of Pg (5'-TGTAGATGACTGATGGTGAAAACC-3'; 5'-ACGTCATCC CCACCTTCCTC-3' $)^{18}$ and fimA II genotype (5'-ACAACTATACTTATGACAATGG-3'; $5^{\prime}$-AACCCCGCTCCCTGTATTCCGA-3 $\left.{ }^{\prime}\right)^{7}$. The primers resulted in amplicons of 197 and 257 bp from strains of Pg (\#HW24D-2) and genotype fimA II (\#HW24D-2), respectively, which were used as controls.

Amplification (Biocycler, Biosystems, Curitiba, PR, Brazil) of the $16 \mathrm{~S}$ rDNA was performed with an initial cycle at $94^{\circ} \mathrm{C}$ for $10 \mathrm{~min}$, followed by 30 cycles at $96^{\circ} \mathrm{C}$ for $30 \mathrm{~s}, 55^{\circ} \mathrm{C}$ for $30 \mathrm{~s}$ and $72^{\circ} \mathrm{C}$ for $30 \mathrm{~s}$, with a final extension at $72^{\circ} \mathrm{C}$ for $10 \mathrm{~min}^{17}$. For $\mathrm{Pg}$, amplification was performed with an initial cycle at $95^{\circ} \mathrm{C}$ for $5 \mathrm{~min}$, followed by 30 cycles at $94^{\circ} \mathrm{C}$ for $30 \mathrm{~s}, 58^{\circ} \mathrm{C}$ for $30 \mathrm{~s}$ and $72^{\circ} \mathrm{C}$ for $30 \mathrm{~s}$, followed by a final extension at $72^{\circ} \mathrm{C}$ for $7 \mathrm{~min}^{7}$. For fimA II genotype, amplification was performed with an initial cycle at $95^{\circ} \mathrm{C}$ for $5 \mathrm{~min}$, followed by 35 cycles at $94^{\circ} \mathrm{C}$ for $30 \mathrm{~s}, 58^{\circ} \mathrm{C}$ for $30 \mathrm{~s}$ and $72^{\circ} \mathrm{C}$ for $30 \mathrm{~s}$, followed by a final extension at $72^{\circ} \mathrm{C}$ for $7 \mathrm{~min}^{9}$.

The amplification products were analyzed by electrophoresis on agarose gel. A $1.5 \%$ gel was used to assess the $16 \mathrm{~S}$ rDNA and the presence of $\mathrm{Pg}$, while a $2.0 \%$ gel was used to assess the fimA II genotype. The gels were stained with SYBR ${ }^{\circledR}$ Safe (Invitrogen, São Paulo, SP, Brazil) and photographed (Canon Powershot A640, Canon, USA) under ultraviolet light (LTA/LTB GE, Loccus Biotecnologia, São Paulo, SP, Brazil). PCR was repeated three times for each sample and for each microorganism.

\section{Statistical analysis}

The normality of the data distribution was verified with the Kolmogorov-Smirnov test. Comparisons between clinical 
data and bacterial findings were made with the non-paired t test (for normally distributed data) and the Mann-Whitney test (for non-normally distributed data). The level of significance was determined to be $5 \%$. All data analyses were performed with the software GraphPad Instat (GraphPad Software Inc., San Diego, CA, USA).

\section{Results}

The sample included 45 subjects with GAgP aged 15-40 years (mean: 28.8). The clinical findings of the sample are presented in Table 1.

$P g$ was present in 29 patients (64.4\%) and fimA II genotype in $25(86.2 \%)$ of the 29 subjects testing positive for Pg. Table 2 shows mean periodontal findings according to the presence/absence of $P g$ and fimA II genotype. Statistically significant difference was found for age between $P g+$ and $P g$ - patients. Mean clinical attachment loss was significantly greater at the sampled site for microbial analysis in $\mathrm{Pg}+$ and also in fimA + patients.

Table 1 - Clinical data of the GAgP patients.

\begin{tabular}{ll}
\hline Number of patients & 45 \\
Mean age; age range (years) & $28.8 \pm 5.9 ; 15-40$ \\
Mean number of teeth & $26 \pm 2$ \\
Mean PD fm (mm) & $3.4 \pm 0.7$ \\
Mean CAL fm (mm) & $3.8 \pm 0.9$ \\
Mean PD at sampled site (mm) & $9.0 \pm 1.9$ \\
Mean CAL at sampled site (mm) & $9.9 \pm 2.2$ \\
Mean $\mathrm{Gl}(\%)$ & $12.7 \pm 9.8$ \\
Mean PI (\%) & $32.1 \pm 17.4$ \\
PD $\geq 5 \mathrm{~mm}(\%$ of sites) & $26.5 \pm 14.5$ \\
$\mathrm{PD} \geq 5 \mathrm{~mm}$ (\% of teeth) & $59.0 \pm 20.6$ \\
$\mathrm{CAL} \geq 5 \mathrm{~mm}$ (\% of sites) & $31.7 \pm 17.0$ \\
$\mathrm{CAL} \geq 5 \mathrm{~mm}$ (\% of teeth) & $65.2 \pm 19.1$
\end{tabular}

Values are presented as mean \pm standard deviation.

GAgP: generalized aggressive periodontitis; PD: probing depth; CAL: clinical attachment loss; Gl: gingival index; Pl: plaque index; fm: full mouth.

Table 2 - Characteristics of the patients according to the presence/ absence of the microorganism/genotype studied.

\begin{tabular}{lllll}
\hline & $P g+$ & $P g-$ & fimA II+ & fimA II- \\
\hline $\mathrm{N}$ & 29 & 16 & 25 & 4 \\
Mean age (years) & $30.1 \pm 5.7^{*}$ & $26.3 \pm 5.5$ & $30.9 \pm 5.0$ & $25.5 \pm 8.2$ \\
Mean PD fm (mm) & $3.4+0.5$ & $3.3 \pm 0.9$ & $3.4 \pm 0.5$ & $3.5 \pm 0.6$ \\
Mean CAL fm (mm) & $3.9 \pm 0.8$ & $3.7 \pm 1.1$ & $3.9 \pm 0.8$ & $3.7 \pm 0.7$ \\
$\begin{array}{l}\text { Mean PD at sampled } \\
\text { site(mm) }\end{array}$ & $9.4 \pm 1.8$ & $8.2 \pm 1.8$ & $9.6 \pm 1.9$ & $8.3 \pm 1.3$ \\
Mean CAL at sampled & $10.5 \pm 2.2^{*}$ & $8.8 \pm 1.9$ & $10.8 \pm 2.1^{* *}$ & $8.5 \pm 1.3$ \\
site(mm) & & & & \\
Pl (\%) & $37.3 \pm 16.6$ & $25 \pm 16.5$ & $38.2 \pm 13.3$ & $29.7 \pm 9.7$ \\
$\mathrm{Gl}(\%)$ & $13.5 \pm 11$ & $11.3 \pm 8.3$ & $14.7 \pm 11.3$ & $7.3 \pm 6.5$ \\
\hline
\end{tabular}

Values are presented as mean \pm standard deviation.

*Statistically significant difference $(\mathrm{P}<0.05)$ between $\mathrm{Pg}+$ and $\mathrm{Pg}$ -

** Statistically significant difference $(P<0.05)$ between fimA II+ and fimA II-

$\mathrm{Pg}+$ : presence of Porphyromonas gingivalis; $\mathrm{Pg}-$ : absence of Porphyromonas gingivalis fimA II+: presence of fimA II genotype; fimA II-: absence of fimA II genotype; PD: probing depth; CAL: clinical attachment loss; PI: plaque index; GI: gingival index fm: full mouth.

\section{Discussion}

This study present results to support the idea that $P g$ play an important role in the etiology of $\mathrm{AgP}$. It has been associate to $\mathrm{AgP}$ in certain populations ${ }^{[3,4]}$. Pg was one of the most frequently detected species in AgP Chinese patients, harboring almost a hundred percent of the patients ${ }^{3}$. In the current study $\mathrm{Pg}$ was detected in $64.4 \%$ of the subjects. In addition, fim $A$ II genotype was detected in over $85 \%$ of patients colonized by $P g$. Among the different $P g$ fimbriae genotypes, fimA II is the most virulent and has been related to periodontal disease progression ${ }^{7,19}$ and $\mathrm{AgP}^{3,11}$.

$\mathrm{AgP}$ is often associated with $A a^{2,20}$, however, it has been showed that the virulence of Aa decreases over time ${ }^{21}$. There is evidence that the Aa leukotoxicity decreased in patients with localized aggressive periodontitis ( $\mathrm{LAgP}$ ) originally colonized by highly leukotoxic clones ${ }^{21}$. Another study found an increased prevalence of $A a$ in shallow and intermediate pockets of LAgP patients only, whereas the prevalence of $P g$ was high in both $\mathrm{LAgP}$ and $\mathrm{GAgP}$, suggesting $\mathrm{Aa}$ is predominantly associated with $\mathrm{LAgP}$ while $P g$ is associated with the progression of LAgP and with $\mathrm{GAgP}^{19}$. Once the patients of the current study presenting $\mathrm{Pg}$ are older and presented sites with greater periodontal destruction as well as the ones presenting the fimA II genotype, it can be suggested that over time $P$. gingivalis can play an important role in AgP progression.

The prevalence of $P g$ observed in this study (64.4\%) was lower than the prevalence generally reported in the literature. In three Brazilian studies, $\mathrm{Pg}$ was found in $80 \%^{22}, 86.7 \%^{6}$ and $73.3 \%^{23}$ of AgP patients. In Chile ${ }^{24}$ and in Japan ${ }^{11}$, the prevalence were $88.8 \%$ and $79.8 \%$, respectively. In China, it was even higher, colonizing nearly $100 \%$ of a sample of Chinese AgP patients. The smaller prevalence of $\mathrm{Pg}$ found in the present study also may be related by the fact that our samples were collected from the site of greatest probing depth in each patient, whereas the above-cited studies pooled samples from multiple sites. However, a study comparing samples from one against three deepest periodontal sites, evaluated by molecular biology technique, concluded that there was no difference for the frequency of $\mathrm{Pg}^{25}$.

To our knowledge, only two studies reported prevalences for $P g$ fimA genotypes in patients with $\mathrm{AgP}^{3,11}$. The prevalence of fim A II genotype observed in this study may be considered high (86.2\%) compared to another results, that evaluated the prevalence of six genotypes in $\mathrm{AgP}$ patients and found fimA II to be the most common type: $40.5 \%$ and $47.3 \%{ }^{11}$. These two studies analyzed patients with characteristics similar to ours, including mean age and periodontal destruction. However, while the number of AgP patients recruited was greater to Feng et al. ${ }^{3}$, who studied 81 Chinese patients, Miura et al. ${ }^{11}$ analysed only 18 Japanese patients.

FimA II genotype is considered particularly virulent due to its association with periodontal destruction ${ }^{26}$. FimA II adheres to and invades human epithelial cells more efficiently than other genotypes $^{8}$. Studies also demonstrated that fimA II genotype can induce a stronger inflammatory reaction ${ }^{27,28}$. In addition, when comparing $P g$ genotypes in periodontitis patients with diabetes after periodontal treatment, fimA II was detected only in subjects with increased levels of glycated hemoglobin (HbAlc), while improvements in $\mathrm{HbAlc}$ values were observed in subjects without 
type II clones, suggesting that glycemic levels in diabetes are affected by the persistence of $P g$ fim $A$ II genotype ${ }^{29}$. These studies suggest that fim A II genotype is an important factor of virulence in $P g$ and may play a role in inflammatory response not only in periodontitis, but also in systemic diseases ${ }^{28,29}$.

In our study, the presence of $P g$ and genotype fimA II was associated with greater clinical attachment loss at the site sampled for microbial analysis. These findings are supported by studies that observed a higher prevalence of $P g$ at sites with greater attachment loss in patients with chronic periodontitis ${ }^{4,13}$, and that founded the prevalence of fimA II genotype to be greater in deeper periodontal pockets $^{7,26}$. Therefore, the presence of this genotype may be used to identify individuals at risk, establish plan treatments and prognosis. These findings can also be useful in the development of novel treatment strategies, such as passive immunotherapy ${ }^{30}$.

In conclusion, in the present sample of Brazilians with GAgP, the prevalence of $P g$ and fimA II genotype was high. Additionally, $P g$ was more prevalent among slightly older patients and at sites with greater periodontal destruction, and fimA II genotype was more present in sites with greater clinical attachment loss.

\section{Conflict of interest}

No potential conflict of interest relevant to this article was reported.

\section{Acknowledgements}

This study was supported by grants from CNPq (478161/20077) and CAPES (PROCAD NF 2313/2008). The authors would like to thank the Oral Microbiology group from Academic Centre for Dentistry Amsterdam (ACTA) for providing Porphyromonas gingivalis strains.

\section{References}

1. Albandar JM. Aggressive periodontitis : case definition and diagnostic criteria. Periodontol 2000. 2014 Jun;65(1):13-26. doi: 10.1111/prd.12014.

2. American Academy of Periodontology. Parameter on aggressive periodontitis. J Periodontol. 2000 May;71(5 Suppl):867-9.

3. Feng $X$, Zhang $L, X u L$, Meng $H$, Lu R, Chen Z, et al. Detection of Eight Periodontal Microorganisms and Distribution of Porphyromonas gingivalis fimA Genotypes in Chinese Patients With Aggressive Periodontitis. J Periodontol. 2014 Jan;85(1):150-9. doi: 10.1902/ jop.2013.120677.

4. Yano-Higuchi K, Takamatsu N, He T, Umeda M, Ishikawa I. Prevalence of Bacteroides forsythus, Porphyromonas gingivalis and Actinobacillus actinomycetemcomitans in subgingival microflora of Japanese patients with adult and rapidly progressive periodontitis. J Clin Periodontol. 2000 Aug;27(8):597-602.

5. Haubek D, Johansson A. Pathogenicity of the highly leukotoxic JP2 clone of Aggregatibacter actinomycetemcomitans and its geographic dissemination and role in aggressive periodontitis. J Oral Microbiol. 2014 Aug 14;6. doi: 10.3402/jom.v6.23980.

6. Missailidis CG, Umeda JE, Ota-Tsuzuki C, Anzai D, Mayer MP. Distribution of fimA genotypes of Porphyromonas gingivalis in subjects with various periodontal conditions. Oral Microbiol Immunol. 2004 Aug;19(4):224-9.

7. Amano A, Nakagawa I, Kataoka K, Morisaki I, Hamada S. Distribution of Porphyromonas gingivalis strains with fimA genotypes in periodontitis patients. J Clin Microbiol. 1999 May;37(5):1426-30.

8. Hamada S, Amano A, Kimura S, Nakagawa I, Kawabata S, Morisaki I. The importance of fimbriae in the virulence and ecology of some oral bacteria. Oral Microbiol Immunol. 1998 Jun;13(3):129-38.

9. Amano A, Kuboniwa M, Nakagawa I, Akiyama S, Morisaki I, Hamada $S$. Prevalence of specific genotypes of Porphyromonas gingivalis fimA and periodontal health status. J Dent Res. 2000 Sep;79(9):1664-8.

10. Nakagawa I, Amano A, Ohara-Nemoto Y, Endoh N, Morisaki I, Kimura $S$, et al. Identification of a new variant of fimA gene of Porphyromonas gingivalis and its distribution in adults and disabled populations with periodontitis. J Periodontal Res. 2002 Dec;37(6):425-32.

11. Miura M, Hamachi T, Fujise $O$, Maeda K. The prevalence and pathogenic differences of Porphyromonas gingivalis fimA genotypes in patients with aggressive periodontitis. J Periodontal Res. 2005 Apr;40(2):147-52.

12. Brígido JA, da Silveira VR, Rego RO, Nogueira NA. Serotypes of Aggregatibacter actinomycetemcomitans in relation to periodontal status and geographic origin ofindividuals-a review of the literature. Med Oral Patol Oral Cir Bucal. 2014 Mar;19(2):184-91.

13. Hamlet SM, Cullinan MP, Westerman B, Lindeman M, Bird PS Palmer J, et al. Distribution of Actinobacillus actinomycetemcomitans, Porphyromonas gingivalis and Prevotella intermedia in an Australian population. J Clin Periodontol. 2001 Dec;28(12):1163-71.

14. Ainamo J, Bay I. Problems and proposals for recording gingivitis and plaque. Int Dent J. 1975 Dec;25(4):229-35.

15. Cortelli SC, Costa FO, Kawai T, Aquino DR, Franco GCN, Ohara $\mathrm{K}$, et al. Diminished treatment response of periodontally diseased patients infected with the JP2 clone of Aggregatibacter (Actinobacillus) actinomycetemcomitans. J Clin Microbiol. 2009 Jul;47(7):2018-25. doi: 10.1128/JCM.00338-09.

16. Silveira VR, Nogueira MV, Nogueira NA, Lima V, Furlaneto FA, Rego RO Leukotoxicity of Aggregatibacter actinomycetemcomitans in generalized aggressive periodontitis in Brazilians and their family members. J Appl Oral Sci. 2013 Sep-Oct;21(5):430-6. doi: 10.1590/1679-775720130252.

17. Wilson $\mathrm{KH}$, Blitchington RB, Greene RC. Amplification of bacterial $16 \mathrm{~S}$ ribosomal DNA with polymerase chain reaction. J Clin Microbiol. 1990 Sep;28(9):1942-6.

18. Tran SD, Rudney JD. Multiplex PCR using conserved and speciesspecific 16S rRNA gene primers for simultaneous detection of Actinobacillus actinomycetemcomitans and Porphyromonas gingivalis. J Clin Microbiol. 1996 Nov;34(11):2674-8.

19. Faveri M, Figueiredo LC, Duarte PM, Mestnik MJ, Mayer MP, Feres M. Microbiological profile of untreated subjects with localized aggressive periodontitis. J Clin Periodontol. 2009 Sep;36(9):739-49. doi: 10.1111/j.1600-051X.2009.01449.x.

20. Li Y, Feng $X, X u L$, Zhang L, Lu R, Shi D, et al. Oral microbiome in chinese patients with aggressive periodontitis and their family members. J Clin Periodontol. 2015 Nov;42(11):1015-23. doi: 10.1111/jcpe.12463.

21. Haraszthy VI, Hariharan G, Tinoco EM, Cortelli JR, Lally ET, Davis $E$, et al. Evidence for the role of highly leukotoxic Actinobacillus actinomycetemcomitans in the pathogenesis of localized juvenile and other forms of early-onset periodontitis. J Periodontol. 2000 Jun; 71(6):912-22

22. Cortelli JR, Cortelli SC, Jordan S, Haraszthy VI, Zambon JJ. Prevalence of periodontal pathogens in Brazilians with aggressive or chronic periodontitis. J Clin Periodontol. 2005 Aug;32(8):860-6.

23. Imbronito AV, Okuda OS, Freitas MN, Lotufo RFM, Nunes FD. Detection of herpesviruses and periodontal pathogens in subgingival plaque of patients with chronic periodontitis, generalized aggressive periodontitis, or gingivitis. J Periodontol. 2008 Dec;79(12):2313-21. doi: 10.1902/ jop.2008.070388.

24. Gajardo M, Silva N, Gomez L, Leon R, Parra B, Contreras A, et al. Prevalence of periodontopathic bacteria in aggressive periodontitis 
patients in a Chilean population. J Periodontol. 2005 Feb;76(2):289-94.

25. Krigar DM, Kaltschmitt J, Krieger JK, Eickholz P. Two subgingival plaque-sampling strategies used with RNA probes. J Periodontol. 2007 Jan;78(1):72-8.

26. Zhao L, Wu YF, Meng S, Yang H, OuYang YL, Zhou XD. Prevalence of fimA genotypes of Porphyromonas gingivalis and periodontal health status in Chinese adults. J Periodontal Res. 2007 Dec;42(6):511-7.

27. Kato T, Kawai S, Nakano K, Inaba H, Kuboniwa M, Nakagawa I, et al. Virulence of Porphyromonas gingivalis is altered by substitution of fimbria gene with different genotype. Cell Microbiol. $2007 \mathrm{Mar}$;9(3):753-65.

28. Sugano N, Ikeda K, Oshikawa M, Sawamoto $Y$, Tanaka H, Ito K.
Differential cytokine induction by two types of Porphyromonas gingivalis. Oral Microbiol Immunol. 2004 Apr;19(2):121-3.

29. Makiura N, Ojima M, Kou Y, Furuta N, Okahashi N, Shizukuishi S, et al. Relationship of Porphyromonas gingivalis with glycemic level in patients with type 2 diabetes following periodontal treatment. Oral Microbiol Immunol. 2008 Aug;23(4):348-51. doi: 10.1111/j.1399302X.2007.00426.x.

30. Hijiya T, Shibata Y, Hayakawa M, Abiko Y. A monoclonal antibody against fimA type II Porphyromonas gingivalis inhibits IL-8 production in human gingival fibroblasts. Hybridoma (Larchmt). 2010 Jun;29(3):201-4. doi: 10.1089/hyb.2009.0109. 